\title{
Effects of stimulus parameters on motor seizure duration in electroconvulsive therapy
}

\author{
This article was published in the following Dove Press journal: \\ Neuropsychiatric Disease and Treatment \\ 29 May 2017 \\ Number of times this article has been viewed
}

\author{
Sung Woo Joo \\ Yeon $\mathrm{Ho}$ Joo \\ Chang Yoon Kim \\ Jung Sun Lee \\ Department of Psychiatry, University \\ of Ulsan College of Medicine, Asan \\ Medical Center, Seoul, Korea
}

Objective: This study examined the effect of stimulus parameters on the occurrence of adequate seizures and reconsidered the factors related to motor seizure duration.

Methods: The medical records of 187 patients who received ECT in Asan Medical Center from January 2007 to May 2014 were retrospectively reviewed. The starting stimulus dose was determined using a preselected-dose method and the cutoff value to determine the adequate motor seizure duration was 20-25 seconds. The association between seizure parameters and the occurrence of adequate seizure was assessed with logistic regression using a generalized estimating equation.

Results: Age $(P<0.001)$, use of mood stabilizers $(P=0.002)$, and benzodiazepine $(P<0.001)$ were significantly lower in sessions with an adequate seizure duration but use of antidepressants $(P<0.001)$ and clozapine $(P=0.025)$ were significantly higher in sessions with an adequate seizure duration. In the generalized estimating equation analyses, after adjustment for age, benzodiazepine dose, and lamotrigine use, charge (odds ratio [OR] $=0.999 ; 95 \%$ confidence interval $[\mathrm{CI}], 0.998-1.000 ; P=0.005)$, and train duration $(\mathrm{OR}=0.632 ; 95 \% \mathrm{CI}, 0.490-0.817$; $P<0.001)$ were significantly associated with the occurrence of adequate seizure.

Discussion: Stimulus charge and train duration are significantly associated with motor seizure duration. However, train duration appears to have a greater effect on motor seizure duration. Additionally, age, benzodiazepine dose, and lamotrigine use independently affect motor seizure duration.

Keywords: electroconvulsive therapy, seizure duration, seizure parameter, age, lamotrigine, benzodiazepine

\section{Introduction}

Electroconvulsive therapy (ECT) has become an important treatment option for many psychiatric disorders, particularly major depressive disorder, which has been most frequently indicated for ECT. Recently, the importance of ECT has been demonstrated in the treatment of bipolar depression and schizophrenia. In one previous study of patients with bipolar depression, the response rate was significantly higher in the ECT group than in the pharmacological treatment group. ${ }^{1}$ It has been reported that the combination of ECT with pharmacotherapy was found to be most effective in patients with schizophrenia who were nonresponsive to prior pharmacotherapy. ${ }^{2}$ Furthermore, the indications for ECT have been progressively extended to include post-traumatic stress disorder, treatment-resistant obsessive compulsive disorder, treatment-resistant dyskinesia, and treatment-resistant Tourette's syndrome. ${ }^{3,4}$

The motor seizure duration has been considered as a standard for determining the therapeutic adequacy, and a motor seizure lasting 20-25 seconds at minimum has been typically recommended. ${ }^{5}$ Stimulus dose, age, sex, treatment number, and psychotropic 
medication affect seizure duration. Age and treatment number are inversely correlated with seizure duration, and seizure threshold is higher in men relative to women. ${ }^{6-9}$ Each psychotropic medication has an effect on seizure threshold by increasing or decreasing it, and anesthetics for sedating patients during ECT also influence this threshold. ${ }^{10-14}$

Stimulus dose has been known as the important factor related to motor seizure duration. The stimulus dose, which is the quantity of electrical stimulus to produce a seizure, has been considered as the stimulus charge. The stimulus charge is calculated using the following summary metric: stimulus charge equals the product of the current amplitude, pulse width, pulse frequency, and train duration, $($ charge $)=($ current amplitude $)$ $\times($ pulse width $) \times($ pulse frequency $) \times($ train duration $)$. The train duration is the total time in which the electrical power is delivered. The method that considered the stimulus charge as the stimulus dose has been verified in many studies. ${ }^{15}$ However, it has been pointed out that the individual parameters have distinct neurophysiological effects on motor seizure duration, and the method that regards the stimulus charge as the stimulus dose runs a risk of ignoring separate roles. ${ }^{15}$

Clinical practice regarding ECT shows variability according to region and ethnicity. While this is mostly attributed to sociocultural factors, ${ }^{16}$ evidence exists suggesting that ethnic factors might also affect biological variables such as seizure threshold. ${ }^{17,18}$ In Asian countries, the ECT administration has been on the increase recently, with marked variation in the prevalence between them. ${ }^{19}$ To the best our knowledge, evidences about factors affecting the ECT stimulus dose do not exist in Korea. Furthermore, little is known about the relationship between stimulus parameters and motor seizure duration. Therefore, this study examined the association between stimulus parameters and motor seizure duration.

\section{Methods}

In this study, the medical records of 187 patients who received ECT in Asan Medical Center from January 2007 to May 2014 were retrospectively reviewed. Information on patient demographics, medications, and the stimulus parameters and seizure durations of sessions from electronic medical records was collected. The psychotropic medication dosage was adopted as the average dosage during the 2 days before each session. Sessions that lacked data on stimulus parameters were excluded. The study design was approved by Asan Medical Center Institutional Review Board (File number: S2017-0492) and exempted from the requirement for written informed consent because de-identified patients' data acquired during routine care were used.

\section{ECT procedure}

ECT was administered to anesthetized patients who were given muscle relaxants. The anesthesia procedure for ECT included preoxygenation, and the anesthetic agents were thiopental for induction and succinylcholine as the muscle relaxant. However, ketamine, etomidate, and propofol were used in some sessions to increase seizure duration or to improve clinical outcomes.

Treatment was delivered with a MECTA Spectrum5000Q device (MECTA Corporation, Tualatin, OR, USA). All the patients were treated with bitemporal electrode placement. Initial dose was quantified using the preselected-dose method, which was according to MECTA Corporation and revised by the ECT council. This approach considered age and sex to determine the stimulus parameters for the first session based on the previous studies ${ }^{8,20-23}$ (Table 1). Subsequent sessions kept the previous parameters as long as the motor seizure lasted longer than 20-25 seconds. However, if the patients had complications that necessitated the adjustment of parameters during the course or an inadequate seizure occurred, clinicians adjusted the parameters. Motor seizure duration was estimated by the cuff method, which prevents muscle relaxants from reaching the right lower extremity. The length of the seizure was determined by the observation of clonic movements in the right lower limb. Additionally, electroencephalogram (EEG) recordings were performed to evaluate the adequacy of the seizure. The cutoff value to determine an adequate motor seizure duration was 20-25 seconds. ${ }^{24}$ Psychotropic medications decreasing seizure duration were reduced to the minimum possible when ECT was to be provided.

\section{Statistical analysis}

Analyses were performed using the Statistical Package for the Social Sciences (SPSS for Windows; IBM Corporation, Armonk, NY, USA), version 21. A chi-square test for categorical variables and Mann-Whitney test for continuous variables were used to compare age, sex, psychotropic medications, stimulus parameters, and numbers of sessions and

Table I Stimulus parameters in the first session

\begin{tabular}{llllll}
\hline $\begin{array}{l}\text { Age } \\
\text { (years) }\end{array}$ & Sex & $\begin{array}{l}\text { Pulse } \\
\text { width }(\mathbf{m s})\end{array}$ & $\begin{array}{l}\text { Frequency } \\
(\mathbf{H z})\end{array}$ & $\begin{array}{l}\text { Train } \\
\text { duration }(\mathbf{s})\end{array}$ & $\begin{array}{l}\text { Current } \\
(\mathbf{m A})\end{array}$ \\
\hline$<30$ & Female & $\mathrm{I} .4$ & 60 & $\mathrm{I}$ & 0.7 \\
& Male & $\mathrm{I} .4$ & 70 & $\mathrm{I}$ & 0.7 \\
\multirow{2}{*}{$30-60$} & Female & $\mathrm{I} .4$ & 70 & $\mathrm{I} .25$ & 0.75 \\
& Male & $\mathrm{I} .4$ & 80 & $\mathrm{I} .25$ & 0.75 \\
$>60$ & Female & $\mathrm{I} .4$ & 80 & $\mathrm{I} .5$ & 0.75 \\
& Male & $\mathrm{I} .4$ & 90 & $\mathrm{I} .5$ & 0.75 \\
\hline
\end{tabular}


courses between sessions with adequate seizure durations and with inadequate seizure durations. The effects of the variables on the occurrence of adequate seizure duration were evaluated with logistic regression using the generalized estimating equation that accounted for clustering of observations in the same patient. The multivariate analysis included the variables found to be significant in the univariate analysis. To clarify the effect of stimulus parameters, the multivariate analysis for each stimulus parameter was individually performed after adjusting for variables other than stimulus parameters that were significant in the univariate analysis. Initial stimulus parameters were determined according to the age group the subject belonged (Table 1), therefore a stratification analysis according to age was performed to adjust for the effect of age group on the occurrence of adequate seizure duration.

\section{Results}

This study comprised 79 male and 108 female patients with the DSM- $V$ diagnosis of major depressive disorder $(\mathrm{n}=71)$, schizophrenia $(n=45)$, bipolar disorder $(n=39)$, schizoaffective disorder $(n=17)$, unspecified schizophrenia spectrum and other psychotic disorder $(n=9)$, obsessive-compulsive disorder $(n=3)$, catatonia associated with brief psychotic disorder $(n=1)$, somatic symptom disorder $(n=1)$, and anorexia nervosa $(n=1)$. The mean patient age was 42.30 (standard deviation $[\mathrm{SD}]=17.08$ ) years.

Excluding the 45 sessions in which the stimulus parameter was not recorded, a total of 1,868 sessions were included. There were 183 sessions in which the stimulus parameters were adjusted because of inadequate seizure duration in the session that was performed on the same day. The most commonly adjusted stimulus parameter was train duration $(n=132,72.1 \%)$, followed by frequency $(n=98,53.6 \%)$, current $(n=45,24.6 \%)$, and pulse width $(n=10,5.5 \%)$. The means and SDs of adjustments in each stimulus parameter were $0.39 \pm 0.22$ (train duration), $11.4 \pm 4.1$ (frequency), 88.9 \pm 53.2 (current), and 0.09 \pm 0.11 (pulse width).

Table 2 lists various study characteristics, including age, sex, number of courses and sessions, stimulus parameters, and the use and dose of concurrent psychotropic medications in sessions with adequate and inadequate seizure durations. Sessions with an adequate seizure duration showed a significantly lower age $(P<0.001)$; less use of benzodiazepine $(P<0.001)$, mood stabilizers $(P=0.002)$, and lamotrigine $(P<0.001)$; and more use of antidepressants $(P<0.001)$ and clozapine $(P=0.025)$. The charge (mean \pm $\mathrm{SD}, 274.3 \pm 160.4$ vs $359.85 \pm 220.86 \mathrm{mC}, P<0.001)$, pulse frequency (mean $\pm \mathrm{SD}, 80.8 \pm 15.81$ vs $88.44 \pm 17.58 \mathrm{~Hz}$,
$P<0.001$ ), train duration (mean $\pm \mathrm{SD}, 1.48 \pm 0.5$ vs $1.82 \pm 0.73$ seconds, $P<0.001$ ), and current (mean $\pm \mathrm{SD}, 763.96 \pm 51.27$ vs $770.27 \pm 50.76 \mathrm{~mA}, P=0.007)$ were significantly lower in sessions with an adequate seizure duration. The aim was to examine the differences in the doses of psychotropic medications between the sessions with an adequate seizure duration and the sessions with an inadequate seizure duration. The benzodiazepine dose was calculated as the lorazepam equivalent dose. Benzodiazepine $(P<0.001)$ and clozapine $(P=0.021)$ doses were significantly different between sessions. There were too few sessions to investigate the differences in the doses of psychotropic medications other than benzodiazepine and clozapine. The results of other variables are summarized in Table 2.

Table 3 presents the results of the generalized estimating equation analyses. In the univariate analysis, charge $(P<0.001)$, frequency $(P=0.001)$, train duration $(P<0.001)$, age $(P<0.001)$, age group $(30-60$ years: $P=0.011 ;>60$ years: $P<0.001)$, benzodiazepine dose $(\leq 1: P=0.046 ;>1$ : $P<0.001)$, use of benzodiazepine $(P=0.001)$, mood stabilizers $(P=0.002)$, and lamotrigine $(P<0.001)$ were significant variables. In the multivariate analysis including factors that were significantly associated with the occurrence of adequate seizure duration in the univariate analysis, train duration (odds ratio [OR], 0.444; 95\% confidence interval [CI], 0.263-0.749), age group (30-60 years: OR, 0.572; 95\% CI, 0.372-0.882; >60 years: OR, 0.290; 95\% CI, $0.162-0.502)$, benzodiazepine dose ( $\leq 1$ : OR, $0.731 ; 95 \%$ CI, 0.551-0.970; >1: OR, 0.434; 95\% CI, 0.301-0.626), and lamotrigine use (OR, 0.283; 95\% CI, 0.145-0.552) remained significant variables. After adjustment for age, benzodiazepine dose, and lamotrigine use, the analysis showed that charge (OR, 0.999; 95\% CI, 0.998-1.000; $P=0.005)$ and train duration (OR, 0.632; 95\% CI, 0.490-0.817; $P<0.001)$ were significantly associated with the occurrence of adequate seizure duration. Considering the adjustment of stimulus parameters, the same analyses were conducted after excluding the 183 sessions in which the stimulus parameters were adjusted because of inadequate seizure duration in the session that was performed on the same day. After adjustment for age, benzodiazepine dose, and lamotrigine use, the association of charge (OR, 0.999; 95\% CI, $0.998-1.000 ; P=0.005)$ and train duration $(\mathrm{OR}, 0.601 ; 95 \%$ CI, $0.450-0.802 ; P=0.001)$ with the occurrence of adequate seizure duration still remained.

The sessions were divided into three groups according to age. The above analyses were conducted in each group (Table 4). In patients younger than 30 years, none of the 
Table 2 Characteristics of the sessions ${ }^{\ddagger}$

\begin{tabular}{|c|c|c|c|c|}
\hline Variables & $\begin{array}{l}\text { Sessions with inadequate } \\
\text { seizure durations } \\
(n=519)\end{array}$ & $\begin{array}{l}\text { Sessions with adequate } \\
\text { seizure durations } \\
(n=I, 349)\end{array}$ & $\begin{array}{l}\text { z score } \\
\text { or } \\
\chi^{2}(\mathrm{df})\end{array}$ & $P$-value \\
\hline Age (mean $\pm S D)$ (years) & $48.18 \pm|7.5|$ & $39.48 \pm 16.43$ & -9.57 & $<0.001$ \\
\hline$<30(\%)$ & 21.0 & 37.4 & $104.28(2)$ & $<0.001$ \\
\hline $30-60(\%)$ & 44.9 & 48.1 & & \\
\hline$>60(\%)$ & 34.1 & 14.5 & & \\
\hline Male $(\%)$ & 58.3 & 53.7 & $3.26(1)$ & 0.071 \\
\hline Number of courses (mean \pm SD) & $1.68 \pm 1.70$ & $1.64 \pm 1.6 \mathrm{I}$ & -0.02 & 0.984 \\
\hline Number of sessions (mean \pm SD) & $4.31 \pm 2.89$ & $4.49 \pm 3.31$ & -0.525 & 0.600 \\
\hline Charge $(m C)($ mean $\pm S D)$ & $359.85 \pm 220.86$ & $274.3 \pm 160.4$ & -9.951 & $<0.001$ \\
\hline Pulse width $(\mathrm{ms})($ mean \pm SD) & $1.4 \pm 0.07$ & $\mathrm{I} .4 \mathrm{I} \pm 0.05$ & -1.046 & 0.296 \\
\hline Frequency $(\mathrm{Hz})($ mean $\pm \mathrm{SD})$ & $88.44 \pm 17.58$ & $80.8 \pm|5.8|$ & -8.855 & $<0.001$ \\
\hline Train duration $(\mathrm{s})$ (mean $\pm \mathrm{SD}$ ) & $1.82 \pm 0.73$ & I. $.48 \pm 0.5$ & -10.659 & $<0.001$ \\
\hline Current $(\mathrm{mA})($ mean $\pm S D)$ & $770.27 \pm 50.76$ & $763.96 \pm 51.27$ & -2.683 & 0.007 \\
\hline Use of benzodiazepine (\%) & 37.8 & 26.9 & $21.07(1)$ & $<0.001$ \\
\hline Benzodiazepine dose ${ }^{\ddagger \ddagger}($ mean $\pm S D)$ & $1.39 \pm 1.13$ & $1.17 \pm 0.86$ & -2.352 & 0.02 \\
\hline $0(\%)$ & 62.2 & 73.1 & $26.09(2)$ & $<0.001$ \\
\hline$\leq \mathrm{I}(\%)$ & 21.4 & 18.2 & & \\
\hline$>I(\%)$ & 16.4 & 8.7 & & \\
\hline Use of antipsychotics (\%) & 14.3 & 11.7 & $2.23(1)$ & 0.135 \\
\hline Use of aripiprazole (\%) & 10.2 & 8.0 & $2.32(1)$ & 0.128 \\
\hline Use of olanzapine (\%) & 37.4 & 37.9 & $0.04(1)$ & 0.842 \\
\hline Use of quetiapine (\%) & 38.7 & 35.1 & $2.18(1)$ & 0.140 \\
\hline Use of clozapine (\%) & 13.7 & 18.0 & $5.03(1)$ & 0.025 \\
\hline Clozapine dose (mean \pm SD) & $240.32 \pm|42.3|$ & $268.0 \pm 146.26$ & -1.419 & 0.16 \\
\hline $0(\%)$ & 86.3 & 82.0 & $7.75(2)$ & 0.021 \\
\hline$>200(\%)$ & 5.2 & 4.9 & & \\
\hline$\geq 200$ (\%) & 8.5 & 13.1 & & \\
\hline Use of mood stabilizers (\%) & 11.0 & 6.6 & $10.00(1)$ & 0.002 \\
\hline Use of lithium (\%) & 1.9 & 1.5 & $0.11(1)$ & 0.744 \\
\hline Use of lamotrigine (\%) & 9.1 & 3.8 & $20.98(I)$ & $<0.001$ \\
\hline Use of antidepressants (\%) & 6.1 & 48.7 & $21.59(1)$ & $<0.001$ \\
\hline
\end{tabular}

Notes: ${ }^{\ddagger}$ Analyzed by Mann-Whitney test or chi-square test. ${ }^{\ddagger}$ Calculated as the lorazepam equivalent dose; the difference in the mean dose of benzodiazepine was analyzed using the Mann-Whitney test; and the differences among the three groups $(0,<1 \mathrm{mg} / \mathrm{day}$, and $>1 \mathrm{mg} /$ day $)$ were analyzed by the chi-square test.

Abbreviations: df, degree of freedom; SD, standard deviation.

stimulus parameters were significant. Charge (OR, 0.999; 95\% CI, 0.997-1.000; $P=0.038$ ) and train duration (OR, $0.521 ; 95 \% \mathrm{CI}, 0.351-0.773 ; P=0.001)$ were significant in patients between 30 and 60 years of age. Charge (OR, 0.999; 95\% CI, 0.998-1.000; $P=0.040)$ remained significant in patients older than 60 years.

\section{Discussion}

The effects of stimulus parameters on motor seizure duration in ECT were investigated and the factors that have been associated with motor seizure duration were reexamined. The results indicated that charge and train duration were significant seizure parameters, which were inversely associated with the occurrence of adequate seizure duration. A significant association between charge and train duration and the occurrence of adequate seizure duration was only seen in patients who were between 30 and 60 years of age.
Age, benzodiazepine dose, and lamotrigine use had an inverse effect on motor seizure duration.

The results of generalized estimating equation analyses indicated that charge was significantly associated with the occurrence of adequate seizure duration. However, considering OR for charge, it did not seem that charge was a good predictive factor for an adequate seizure. Train duration was also found to be a significant factor. The results showed a trend toward an occurrence of inadequate seizure duration as the train duration increased. According to the summary metric of stimulus charge, the stimulus charge is positively correlated with stimulus train duration and a longer train duration indicates a stronger stimulus intensity. Consistent with previous studies, the results of this study indicated that increasing stimulus intensity was negatively correlated with the occurrence of adequate seizure duration. ${ }^{7,25}$ A previous retrospective study reported that stimulus intensity is 
Table 3 Odds ratios for associating demographics, psychotropic medications, and stimulus parameters with the occurrence of adequate seizure*

\begin{tabular}{|c|c|c|c|c|}
\hline Variables & $\begin{array}{l}\text { Crude } \\
\text { OR }(95 \% \mathrm{Cl})\end{array}$ & $P$-value & $\begin{array}{l}\text { Adjusted }^{\dagger} \\
\text { OR }(95 \% \mathrm{Cl})\end{array}$ & $P$-value \\
\hline \multicolumn{5}{|l|}{ Stimulus parameters ${ }^{\#}$} \\
\hline Charge $(\mathrm{mC})$ & $0.998(0.998-0.999)$ & $<0.001$ & $0.999(0.998-1.000)$ & 0.005 \\
\hline Pulse width (ms) & $0.914(0.502-1.665)$ & 0.769 & $1.096(0.620-1.940)$ & 0.752 \\
\hline Frequency $(\mathrm{Hz})$ & $0.985(0.975-0.994)$ & 0.001 & $0.993(0.983-1.004)$ & 0.217 \\
\hline Train duration (s) & $0.557(0.44 I-0.705)$ & $<0.001$ & $0.632(0.490-0.817)$ & $<0.001$ \\
\hline Current (mA) & I.03। (0.753-I.4I3) & 0.847 & $1.283(0.912-1.805)$ & 0.153 \\
\hline Age (years) & $0.972(0.963-0.982)$ & $<0.001$ & & \\
\hline$<30$ & I & $<0.001$ & & \\
\hline $30-60$ & $0.60 I(0.406-0.890)$ & 0.011 & & \\
\hline$>60$ & $0.250(0.159-0.394)$ & $<0.001$ & & \\
\hline Sex & $1.126(0.789-1.608)$ & 0.512 & & \\
\hline Number of courses & $0.932(0.847-1.025)$ & 0.145 & & \\
\hline Number of sessions & $0.987(0.945-1.030)$ & 0.544 & & \\
\hline Use of benzodiazepine & $0.679(0.535-0.861)$ & 0.001 & & \\
\hline \multicolumn{5}{|l|}{ Benzodiazepine dose } \\
\hline None & 1 & 0.004 & & \\
\hline$\leq 1$ & $0.759(0.579-0.995)$ & 0.046 & & \\
\hline$>1$ & $0.527(0.373-0.745)$ & $<0.001$ & & \\
\hline Use of antipsychotics & $1.113(0.764-1.621)$ & 0.576 & & \\
\hline Use of aripiprazole & $0.665(0.395-1.118)$ & 0.123 & & \\
\hline Use of clozapine & $1.189(0.760-1.861)$ & 0.448 & & \\
\hline Use of olanzapine & I.I29 (0.8I8-I.559) & 0.459 & & \\
\hline Use of quetiapine & $0.846(0.614-1.164)$ & 0.304 & & \\
\hline Use of mood stabilizers & $0.404(0.226-0.721)$ & 0.002 & & \\
\hline Use of lamotrigine & $0.239(0.125-0.459)$ & $<0.001$ & & \\
\hline Use of lithium & $0.682(0.220-2.109)$ & 0.506 & & \\
\hline Use of antidepressants & $0.799(0.595-1.073)$ & 0.136 & & \\
\hline
\end{tabular}

Notes: *Evaluated with logistic regression using a generalized estimating equation that accounted for clustering of observations in the same patient. ${ }^{\dagger}$ Adjusted for age, benzodiazepine dose, and lamotrigine use. "Frequency and train duration were considered as continuous variables; pulse width was dichotomized by 1.5 ms; and current was dichotomized by $800 \mathrm{~mA}$.

Abbreviations: $\mathrm{Cl}$, confidence interval; OR, odds ratio.

inversely associated with motor seizure duration. ${ }^{25}$ Another study reported that stimulus intensity is negatively correlated with motor seizure duration, particularly in the clonic phase. ${ }^{7}$
It is known that seizure threshold may increase during a course of treatment. ${ }^{26-28}$ It might be a possible explanation for the results that, as seizure threshold increased during a course, seizure duration became inadequate and the increase

Table 4 Odds ratios for associating stimulus parameters with the occurrence of adequate seizure in age-dependent subgroups*

\begin{tabular}{|c|c|c|c|c|c|c|}
\hline \multirow[t]{2}{*}{$\begin{array}{l}\text { Stimulus } \\
\text { parameters }^{\#}\end{array}$} & \multicolumn{3}{|l|}{$\begin{array}{l}\text { Crude } \\
\text { OR }(95 \% \mathrm{CI})\end{array}$} & \multicolumn{3}{|l|}{$\begin{array}{l}\text { Adjusted }^{\dagger} \\
\text { OR }(95 \% \mathrm{CI})\end{array}$} \\
\hline & $\begin{array}{l}\text { Age }<30 \\
(\mathbf{N}=6 \mid 4)\end{array}$ & $\begin{array}{l}\text { Age } 30-60 \\
(N=882)\end{array}$ & $\begin{array}{l}\text { Age }>60 \\
(\mathbf{N}=372)\end{array}$ & $\begin{array}{l}\text { Age }<30 \\
(\mathbf{N}=614)\end{array}$ & $\begin{array}{l}\text { Age } 30-60 \\
(N=882)\end{array}$ & $\begin{array}{l}\text { Age }>60 \\
(N=372)\end{array}$ \\
\hline Charge (mC) & $\begin{array}{l}1.000 \\
(0.997-1.002)\end{array}$ & $\begin{array}{l}0.999 \\
(0.998-1.000)^{\S}\end{array}$ & $\begin{array}{l}0.999 \\
(0.998-1.000)^{\S}\end{array}$ & $\begin{array}{l}1.001 \\
(0.997-1.005)\end{array}$ & $\begin{array}{l}0.999 \\
(0.997-1.000)^{\S}\end{array}$ & $\begin{array}{l}0.999 \\
(0.997-1.008)^{\S}\end{array}$ \\
\hline Pulse width (ms) & Infinite & $\begin{array}{l}\text { I.I52 } \\
(0.47|-2.8| 4)\end{array}$ & $\begin{array}{l}0.789 \\
(0.375-1.663)\end{array}$ & - & $\begin{array}{l}\text { I. } 206 \\
(0.524-2.777)\end{array}$ & $\begin{array}{l}0.785 \\
(0.358-I .72 I)\end{array}$ \\
\hline Frequency $(\mathrm{Hz})$ & $\begin{array}{l}1.003 \\
(0.976-1.031)\end{array}$ & $\begin{array}{l}0.991 \\
(0.976-1.006)\end{array}$ & $\begin{array}{l}0.992 \\
(0.997-1.008)\end{array}$ & $\begin{array}{l}1.010 \\
(0.978-1.044)\end{array}$ & $\begin{array}{l}0.991 \\
(0.976-1.007)\end{array}$ & $\begin{array}{l}0.991 \\
(0.975-1.007)\end{array}$ \\
\hline Train duration (s) & $\begin{array}{l}0.674 \\
(0.375-1.212)\end{array}$ & $\begin{array}{l}0.524 \\
(0.356-0.773)^{\S}\end{array}$ & $\begin{array}{l}0.765 \\
(0.540-1.084)\end{array}$ & $\begin{array}{l}0.814 \\
(0.364-1.819)\end{array}$ & $\begin{array}{l}0.521 \\
(0.351-0.773)^{\S}\end{array}$ & $\begin{array}{l}0.755 \\
(0.532-1.072)\end{array}$ \\
\hline Current (mA) & $\begin{array}{l}0.900 \\
(0.5 \mid 4-1.574)\end{array}$ & $\begin{array}{l}1.347 \\
(0.851-2.134)\end{array}$ & $\begin{array}{l}\text { I.522 } \\
(0.645-3.588)\end{array}$ & $\begin{array}{l}\text { I.I79 } \\
(0.668-2.083)\end{array}$ & $\begin{array}{l}\text { I.257 } \\
(0.779-2.027)\end{array}$ & $\begin{array}{l}1.548 \\
(0.650-3.686)\end{array}$ \\
\hline
\end{tabular}

Notes: *Evaluated with logistic regression using a generalized estimating equation that accounted for clustering of observations in the same patient. ${ }^{\dagger}$ Adjusted for benzodiazepine dose and lamotrigine use. "Frequency and train duration were considered as continuous variables; pulse width was dichotomized by 1.5 ms; and current was dichotomized by $800 \mathrm{~mA}$. ${ }^{\S P}<0.05$.

Abbreviations: $\mathrm{Cl}$, confidence interval; $\mathrm{OR}$, odds ratio. 
in stimulus dose was required, which led to the positive association between higher charge and train duration and the occurrence of inadequate seizure duration. However, the results showed that, after excluding the sessions in which the stimulus parameters were adjusted after inadequate seizure duration occurred, charge and train duration were still negatively correlated with the occurrence of inadequate seizure duration. It seems that the adjustment of stimulus parameters may not be the factor explaining the negative association between charge and train duration and the occurrence of adequate seizure duration.

This study showed that age, benzodiazepine dose, and lamotrigine use were significantly associated with the occurrence of adequate seizure duration. Consistent with the results of this study, several studies reported that age and benzodiazepine use were negatively correlated with seizure duration. ${ }^{11,29}$ On the contrary, previous studies reported that lamotrigine use did not seem to have a significant influence on neither the seizure duration nor the stimulus dose. ${ }^{30,31}$ In this study, there were 100 sessions with lamotrigine use and dosages ranged from 6.25 to $200 \mathrm{mg} /$ day. The results indicated that lamotrigine use is a significant factor in lowering the seizure duration. However, large prospective studies are needed to confirm the interaction between lamotrigine use and seizure duration in ECT. Use of antipsychotics was not found to be a significant factor in the results. However, many previous studies have reported that clozapine lowers the seizure threshold. ${ }^{10,32}$ The reason of the negative finding might be that 314 sessions with the use of clozapine in this study were too few to reveal the differences in seizure duration in response to antipsychotics.

\section{Strength and limitations}

There were a number of limitations to this study. First, several kinds of anesthetics were used among the study subjects. Thiopental, the most commonly used anesthetic, was administered in 1,740 sessions but etomidate, propofol, and ketamine were used in 86 sessions, 42 sessions, and 11 sessions, respectively. The number of sessions in this study that used anesthetics other than thiopental was too low to compare the effect of individual anesthetics on seizure duration. In previous studies, anesthetics were reported to influence seizure duration differently. ${ }^{13,33,34}$ In one earlier report, anesthesia induced by etomidate, compared to thiopental, increased seizure duration with less stimulus intensity. ${ }^{33}$ Additionally, propofol has been associated with a shorter seizure duration. ${ }^{13,34}$ Therefore, the different kinds of anesthetics could have influenced the findings of this study. However, because of a minority of the sessions with the use of anesthetics other than thiopental, it was not likely that the use of many different anesthetics would have markedly impacted our results. Second, this study included the preselected dosage method, which used age and sex to determine the seizure parameters. In this dosage method, the initial stimulus dose is anticipated to be moderately above the seizure threshold. In the results, it was not possible to explore the association of a near-threshold stimulus dose with the occurrence of adequate seizure duration. However, the preselected dosage method, used in this study, was based on seizure threshold data obtained by the dose-titration method, and provided the initial stimulus dose at least moderately above the initial seizure threshold for the majority of patients. ${ }^{35}$ Additionally, the range of stimulus parameters was narrow. The lack of the variability in the parameters, especially the pulse width, limits the interpretation of its effect on seizure duration in the data. Third, there has been a move regarding the EEG parameters as important as seizure duration when it comes to seizure adequacy. It has been known that the degree of postictal voltage suppression correlates with seizure generalization and therapeutic adequacy, ${ }^{36}$ and the immediate poststimulus and mid-ictal EEG amplitudes correlate with seizure therapeutic adequacy. ${ }^{37}$ In this study, EEG was used supplementarily in measuring seizure duration but the EEG parameters could not be obtained because of poor data quality. Future studies are needed to verify whether the use of EEG parameters may be helpful to tease apart independent factors from treatment-related factors affecting seizure adequacy. Fourth, this was a retrospective study and, therefore, all of the variables affecting seizure duration could not be taken into account. Some variables such as concomitant medications might be affecting the seizure duration but these variables could not be considered, and the details of some sessions could not be obtained.

Despite the above limitations, there were some notable strengths of this study. First, in terms of the time period and numbers treated, this was a large, naturalistic study. Second, the ECT procedure was consistent with regard to the electrode placement and device used. Third, considering the real-life situation in which patients are prescribed psychotropic medications during ECT, this study reflected the typical circumstances seen in routine clinical practice.

\section{Conclusion}

In conclusion, stimulus charge and train duration are significantly associated with adequate seizure duration. However, considering OR for both of these parameters, it appears that 
train duration has more association with motor seizure duration than stimulus charge. It was a counter-intuitive finding that train duration was negatively correlated with the success of adequate seizure. But there is little evidence to explain this finding, therefore further research is needed. Moreover, the results of this study show that age, benzodiazepine dose, and lamotrigine use are independently associated with seizure duration. These factors should be considered in any future investigation of the relationship between stimulus parameters and seizure duration.

\section{Disclosure}

The authors report no conflicts of interest in this work.

\section{References}

1. Schoeyen HK, Kessler U, Andreassen OA, et al. Treatment-resistant bipolar depression: a randomized controlled trial of electroconvulsive therapy versus algorithm-based pharmacological treatment. $\mathrm{Am} J$ Psychiatry. 2015;172(1):41-51.

2. Pompili M, Lester D, Dominici G, et al. Indications for electroconvulsive treatment in schizophrenia: a systematic review. Schizophr Res. 2013;146(1-3):1-9.

3. Watts BV. Electroconvulsive therapy for comorbid major depressive disorder and posttraumatic stress disorder. $J E C T$. 2007;23(2):93-95.

4. Baghai TC, Moller HJ. Electroconvulsive therapy and its different indications. Dialogues Clin Neurosci. 2008;10(1):105-117.

5. Mankad MV, Beyer JL, Krystal A, Weiner RD. Clinical Manual of Electroconvulsive Therapy. Washington, DC: American Psychiatric Publishing, Inc.; 2010.

6. Rasimas JJ, Stevens SR, Rasmussen KG. Seizure length in electroconvulsive therapy as a function of age, sex, and treatment number. $J E C T$. 2007;23(1):14-16.

7. Wang CC, Lin CH, Chiu YC, Tseng CC. The clonic phase of seizures in patients treated with electroconvulsive therapy is related to age and stimulus intensity. Front Psychiatry. 2013;4:166.

8. Sackeim H, Decina P, Prohovnik I, Malitz S. Seizure threshold in electroconvulsive therapy. Effects of sex, age, electrode placement, and number of treatments. Arch Gen Psychiatry. 1987;44(4):355-360.

9. van Waarde JA, Verwey B, van der Mast RC. Meta-analysis of initial seizure thresholds in electroconvulsive therapy. Eur Arch Psychiatry Clin Neurosci. 2009;259(8):467-474.

10. Gazdag G, Barna I, Ivanyi Z, Tolna J. The impact of neuroleptic medication on seizure threshold and duration in electroconvulsive therapy. Ideggyogy Sz. 2004;57(11-12):385-390.

11. Naguib M, Koorn R. Interactions between psychotropics, anaesthetics and electroconvulsive therapy: implications for drug choice and patient management. CNS Drugs. 2002;16(4):229-247.

12. Kellner CH, Nixon DW, Bernstein HJ. ECT-drug interactions: a review. Psychopharmacol Bull. 1991;27(4):595-609.

13. Zahavi GS, Dannon P. Comparison of anesthetics in electroconvulsive therapy: an effective treatment with the use of propofol, etomidate, and thiopental. Neuropsychiatr Dis Treat. 2014;10:383-389.

14. Singh PM, Arora S, Borle A, Varma P, Trikha A, Goudra BG. Evaluation of etomidate for seizure duration in electroconvulsive therapy: a systematic review and meta-analysis. J ECT. 2015;31(4):213-225.

15. Peterchev AV, Rosa MA, Deng ZD, Prudic J, Lisanby SH. Electroconvulsive therapy stimulus parameters: rethinking dosage. J ECT. 2010; 26(3):159-174.
16. Case BG, Bertollo DN, Laska EM, Siegel CE, Wanderling JA, Olfson M. Racial differences in the availability and use of electroconvulsive therapy for recurrent major depression. $J$ Affect Disord. 2012;136(3): 359-365.

17. Yasuda K, Kobayashi K, Yamaguchi M, et al. Seizure threshold and the half-age method in bilateral electroconvulsive therapy in Japanese patients. Psychiatry Clin Neurosci. 2015;69(1):49-54.

18. Dawkins K, Ekstrom RD, Hill MA, Isaacs DL, Golden RN. Ethnicity and seizure threshold. Prog Neuropsychopharmacol Biol Psychiatry. 2000;24(8):1289-1298.

19. Xiang YT, Ungvari GS, Correll CU, et al. Use of electroconvulsive therapy for Asian patients with schizophrenia (2001-2009): trends and correlates. Psychiatry Clin Neurosci. 2015;69(8):489-496.

20. Beale MD. Stimulus dosing methods in electroconvulsive therapy. Psychiatr Ann. 1998;28(9):510-512.

21. Sackeim HA, Decina P, Kanzler M, Kerr B, Malitz S. Effects of electrode placement on the efficacy of titrated, low-dose ECT. Am J Psychiatry. 1987;144(11):1449-1455.

22. Frukacz A, Mitchell P. Fitting the treatment to the patient: recent advances in the practice of electroconvulsive therapy. Aust N Z J Psychiatry. 1995;29(3):484-491.

23. Weiner RD. ECT and seizure threshold: effects of stimulus wave form and electrode placement. Biol Psychiatry. 1980;15(2):225-241.

24. Sadock BJ, Sadock VA, Ruiz P. Kaplan \& Sadock's Synopsis of Psychiatry: Behavioral Sciences/Clinical Psychiatry. 11th ed. Philadelphia, PA: Wolters Kluwer; 2015.

25. Pridmore S, Batt G, Fujiyama H. ECT seizure duration: database information. Ger J Psychiatr. 2011;14(1):35-39.

26. Chung KF. Relationships between seizure duration and seizure threshold and stimulus dosage at electroconvulsive therapy: implications for electroconvulsive therapy practice. Psychiatry Clin Neurosci. 2002;56(5):521-526.

27. Fink M, Petrides G, Kellner C, et al. Change in seizure threshold during electroconvulsive therapy. JECT. 2008;24(2):114-116.

28. Loo CK, Schweitzer I, Pratt C. Recent advances in optimizing electroconvulsive therapy. Aust N Z J Psychiatry. 2006;40(8):632-638.

29. Swartz CM, Michael N. Age-based seizure threshold determination. JECT. 2013;29(1):18-20.

30. Sienaert P, Roelens Y, Demunter H, Vansteelandt K, Peuskens J, Van Heeringen C. Concurrent use of lamotrigine and electroconvulsive therapy. J ECT. 2011;27(2):148-152.

31. Penland HR, Ostroff RB. Combined use of lamotrigine and electroconvulsive therapy in bipolar depression: a case series. J ECT. 2006; 22(2):142-147.

32. Havaki-Kontaxaki BJ, Ferentinos PP, Kontaxakis VP, Paplos KG, Soldatos CR. Concurrent administration of clozapine and electroconvulsive therapy in clozapine-resistant schizophrenia. Clin Neuropharmacol. 2006;29(1):52-56.

33. Ayhan Y, Akbulut BB, Karahan S, et al. Etomidate is associated with longer seizure duration, lower stimulus intensity, and lower number of failed trials in electroconvulsive therapy compared with thiopental. JECT. 2015;31(1):26-30.

34. Rasmussen KG. Propofol for ECT anesthesia: a review of the literature. JECT. 2014;30(3):210-215.

35. Coffey CE, Lucke J, Weiner RD, Krystal AD, Aque M. Seizure threshold in electroconvulsive therapy: I. initial seizure threshold. Biol Psychiatry. 1995;37(10):713-720.

36. Krystal AD, Weiner RD. ECT seizure therapeutic adequacy. Convuls Ther. 1994;10(2):153-164.

37. Nobler MS, Sackeim HA, Solomou M, Luber B, Devanand DP, Prudic J. EEG manifestations during ECT: effects of electrode placement and stimulus intensity. Biol Psychiatry. 1993;34(5):321-330. 


\section{Publish your work in this journal}

Neuropsychiatric Disease and Treatment is an international, peerreviewed journal of clinical therapeutics and pharmacology focusing on concise rapid reporting of clinical or pre-clinical studies on a range of neuropsychiatric and neurological disorders. This journal is indexed on PubMed Central, the 'PsycINFO' database and CAS, and is the official journal of The International Neuropsychiatric Association (INA). The manuscript management system is completely online and includes a very quick and fair peer-review system, which is all easy to use. Visit http://www.dovepress.com/testimonials.php to read real quotes from published authors.

\footnotetext{
Submit your manuscript here: http://www.dovepress.com/neuropsychiatric-disease-and-treatment-journal
} 